\title{
LÝ THUYẾT HÀNH ĐÔ̂NG TƯƠNG GIAO CỦA HABERMAS VÀ GIÁ TRI CỦA NÓ TRONG LĨNH VỤ̉C TRUYỀN THÔNG TRÊN THẾ GIỚI HIỆN NAY
}

\author{
TRUOONG NGỌC LÂN \\ Khoa Lý luận Chính trị, Trường Đại học Công nghiệp thành phố Hồ Chí Minh \\ Lantruong42@gmail.com
}

Tóm tắt: Những năm gần đây, với sự phát triển của internet đã dẫn đến sự bùng nổ mạnh mẽ của truyền thông xã hội, làm thay đổi căn bản hệ sinh thái truyền thông trong thời đại chúng ta. Các phương tiện, hình thức truyền thông mới ra đời ngày một nhiều với những nội dung đa dạng, thông tin mới mẻ và cách truyền đạt phong phú hình thành nên một mạng lưới truyền thông rộng rãi, kết nối mọi người lại với nhau. Tuy nhiên, hệ quả của sự phát triển này là sự bùng nổ thông tin cùng với sự dịch chuyển thông tin với tốc độ chóng mặt gây nên những vấn nạn như thao túng thông tin hay tin giả,v.v... Lý thuyết hành động tương giao (communicative action) của Harbermas - với tư cách là một lý thuyết triết học quan tâm đến hành vi giao tiếp giữa hai hay nhiều người với nhau mà mục đích cuối cùng hướng đến sự thông hiểu, đồng thuận với nhau - sẽ cung cấp một góc nhìn, đồng thời cũng là công cụ giúp cho con người nhìn nhận các vấn đề truyền thông hiện nay một cách đa chiều hơn, rộng hơn từ đó con người có thể cẩn trọng hơn và chắt lọc được những thông tin cần thiết cho bản thân từ vô vàn những thông tin trôi nổi trên mạng lưới truyền thông.

Từ khóa: Bùng nổ thông tin, hành động tương giao, internet, mạng lưới truyền thông, sự thông hiểu, truyền thông xã hội.

\section{HABERMAS'S THEORY OF COMMUNICATIVE ACTION AND IT'S VALUE IN MODERN COMMUNICATION FIELD IN THE WORLD}

\begin{abstract}
In recent years, the development of the internet has led to a strong explosion of social media, fundamentally changing the media ecosystem of our time. More and more new media and forms of communication have emerged with diverse content, new information and variety methods in communication, forming a wide communication network, connecting people together. However, the consequence of this development is the information overload coupled with the information movement at breakneck speed causing problems such as information manipulation or fake news, etc. Harbermas' communicative action - as a philosophical theory concerned with the communication behavior between two or more people whose ultimate goal is towards mutual understanding and consensus - will provide a viewpoint, also a tool to help people see current communication issues in a more multidimensional and broader way, so that people can be more cautious and filter the necessary information for themself from the countless information that floats on the communication network.
\end{abstract}

Keywords: Communicative action, communication network, information overload, internet, mutual understanding, social media.

\section{1. ĐẶT VẤN ĐỀ}

Thế kỷ XXI với sự phát triển mạnh mẽ của mạng internet kéo theo đó là sự ra đời của mạng xã hội đã làm thay đổi căn bản bộ mặt của hoạt động truyền thông. Ngày nay, với sự ra đời của hàng loạt mạng xã hội (Facebook, Instagram, Twitter, YouTube, v.v...), hoạt động truyền thông đã không còn mang tính chất một chiều theo hướng người truyền đạt thông tin đến người tiếp nhận thông tin mà chuyển sang tính đa chiều, tức là giờ đây người tiếp nhận thông tin có quyền phản bác ngược lại, tranh luận về độ xác thực của thông tin mà họ mà họ nhận được, hay người tiếp nhận thông tin lại đồng thời là người truyền đạt thông tin đem thông tin họ nhận được truyền đến cho người khác. Cứ như thế, hoạt động truyền thông hiện đại với sự hỗ trợ của mạng xã hội đã trở thành một hệ sinh thái truyền thông rộng rãi có sự tương tác qua lại giữa mọi người với nhau. Chính sự phát triển này của hoạt động truyền thông đã mở ra một không 
gian giao tiếp rộng lớn trên các nền tảng mạng xã hội, giúp cho con người có thể kết nối, trò chuyện, thảo luận với nhau dễ dàng hơn, ít bị kiềm tỏa hơn.

Habermas gọi không gian này là không gian công (public sphere), và trong thời đại hiện nay ta có thể gọi nó là không gian công trên internet. Tuy nhiên, bên cạnh những lợi ích to lớn, truyền thông hiện đại cũng mang lại những thách thức không hề nhỏ đó là vấn nạn tin giả và sự kiểm soát thông tin. Nếu khồng thể vượt qua được những thách thức này, không gian công sẽ dần bị thuộc địa hóa và mất đi những chức năng cơ bản của nó. Để khắc phục tình trạng này, việc đầu tiên cần làm là nỗ lực nhận biết được đâu là tin giả, đâu là những tin tức đã bị kiểm soát. Lý thuyết hành vi tương giao với nền tảng là lý tính tương giao của Habermas là một trong những công cụ hữu hiệu giúp chúng ta nhận biết được những vấn nạn đó.

\section{LÝ THUYẾT HÀNH VI TƯƠNG GIAO CỦA HABERMAS}

Jurgen Habermas (1929 - ) được nhìn nhận là triết gia đương đại quan trọng bậc nhất của thế kỷ XX vừa qua và thế kỷ XXI hiện thời. "Ông là được biết đến rộng rãi vượt trên các biên giới của châu Âu." [1]. Lý thuyết của Habermas trải dài trên nhiều lĩnh vực từ chính trị, xã hội đến ngôn ngữ, v.v... Trong đó nổi tiếng nhất là lý thuyết về Hành động tuoong giao (Communicative action), lý thuyết bàn về năng lực giao tiếp của con người hướng đến sự thông hiểu lẫn nhau dựa vào nền tảng là lý tính tương giao (communicative reason). Lý thuyết của ông về sau trở thành một trong những lý thuyết nổi tiếng trong xã hội học lẫn ngành truyền thông học.

Nền tảng của lý thuyết tương giao xuất phát từ quan điểm của Habermas về năng lực giao tiếp của con người thông qua ngôn ngữ, cũng chính là năng lực "làm ta vượt ra khỏi tự nhiên, điều làm ta khác biệt với thú vật và cây cỏ" [2]. Xuất phát từ nền tảng đó, Habermas cho rằng con người không ngừng học tập và thực hành ngôn ngữ nhằm hướng đến một sự thông hiểu lẫn nhau, hay "sự hiểu nhau chính là mục đích của sự diễn đạt trong ngôn ngữ." [3]. Tuy nhiên, ngôn ngữ không phải lúc nào cũng hướng đến sự hiểu nhau. Khi thực hiện hành vi nói, ta có thể sử dụng ngôn ngữ để thóa mạ, chửi bới, dẫn tới sự kích động, hiểu lầm lẫn nhau. Vậy để tránh những điều tiêu cực do hành vi nói gây ra, để hành vi nói được quay trở lại với mục đích nguyên thủy của nó là giúp con người hiểu lẫn nhau, Habermas đã đề xuất học thuyết về hành vi tương giao của mình nhằm giúp con người đạt được sự đồng thuận phổ quát mỗi khi thực hiện hành vi nói.

Theo Habermas sự thông hiểu, đồng thuận với nhau trong ngôn ngữ luôn hàm chứa một cấu trúc kép bên trong nó. Theo đó, khi sử dụng ngôn ngữ, người sử dụng có thể chú ý đến một trong hai đặc tính của ngôn ngữ đó là nội dung và tương quan. Nội dung tức là điều mà người nói hoặc người viết đề cập đến thế giới khách quan, Habermas gọi là thành phần mệnh đề trong ngôn ngữ và tương quan là mối quan hệ xã hội mà người nói hay viết thiết lập với người nghe hay đọc, ông gọi thành phần này là thành phần ngôn trung trong ngôn ngữ. Cùng một thành phần mệnh đề giống nhau có thể được ghép với nhiều thành phần ngôn trung khác nhau và ngược lại, cùng một thành phần ngôn trung có thể ghép được với nhiều mệnh đề khác nhau. Trong không ít trường hợp, mệnh đề được đưa ra là khớp với thế giới khách quan nhưng lại bị người nghe, người đọc từ chối tiếp nhận, nguyên nhân là do mối quan hệ xã hội được thiết lập giữa những người tham gia vào đối thoại khiến họ không tin tưởng hay từ chối hiểu lần nhau. Hoặc khi thực hiện hành động phát ngôn, ta lợi dụng mối quan hệ xã hội đã được thiết lập một cách vững chắc, những người tham gia vào đối thoại đều tin tưởng lẫn nhau, để truyền đạt một mệnh đề sai lệch với thế giới khách quan thì sự thông hiểu hay đồng thuận cũng không thể diễn ra trong một cuộc đối thoại như thế. Vậy, để đạt đến sự đồng thuận, cả hai thành phần mệnh đề và ngôn trung trong ngôn ngữ phải được đặt ở tầm quan trọng ngang nhau và cần phải có những yêu sách để đảm bảo rằng những người tham gia vào đối thoại luôn chú ý điều chỉnh hai thành phần ngôn ngữ này trong hành động phát ngôn của mình. Habermas đã chỉ ra bốn yêu sách mà những người tham gia vào đối thoại phải tuân theo để cuộc trò chuyện của họ trở nên có ý nghĩa. Ông gọi đó là yêu sách về giá trị hiệu lực (validity claim).

Yêu sách về giá trị hiệu lực là những cam kết mà người phát ngôn tạo ra (thường là vô tình) nhằm biện minh cho những gì họ đã nói và những gì họ đã làm. Trong lý thuyết của mình, "Habermas nhận diện bốn yêu sách về giá trị hiệu lực" [4], gồm: Ý nghĩa (meaningfulness), tính chân lý (truth), sự trung thực (truthfulness) và "quyền của người nói để nói những gì anh/chị ta nói (hay phát biểu nói chung)." [5]. Tức khi thực hiện hành vi nói, người nói có thể bị thách thức bởi thẩm quyền hay tư cách hoặc khả năng để nói ra một điều gì đó mà người nghe có thể hiểu được, tiếp đến là thách thức liệu những gì được nói ra có 
mang một ý nghĩa nào đó hay không và nó có phù hợp với thế giới khách quan không, cuối cùng những gì được nói ra có phù hợp với suy nghĩ của người nói không hay người thực hiện hành vi nói có thật sự trung thực và chân thành khi tham gia vào đối thoại không. Thiếu đi một trong bốn yêu sách này, cuộc đối thoại hay diễn ngôn sẽ trở nên vô nghĩa hay thậm chí còn không thể gọi đó là một đối thoại bởi nó đã đi chệch khỏi mục đích ban đầu của ngôn ngữ là hướng đến sự thông hiểu và đồng thuận với nhau.

Habermas kết luận nếu tất cả mọi người khi tham gia vào đối thoại đều ngầm giả định bốn yêu sách về giá trị hiệu lực, đồng thời hướng đến sự hiểu nhau thông qua sự thống nhất liên chủ thể về sự hiểu hỗ tương, sự biết hai chiều, sự tín nhiệm song phương và sự đồng ý với nhau thì trong ngôn ngữ quả thật có một xu hướng đưa tới một sự đồng thuận với những lý do thiện hảo. "Và một sự đồng thuận với những lý do thiện hảo không gì khác hơn chính là "lý tính." [6]. Do đó, Habermas đề xuất thuật ngữ lý tính tương giao/giao tiếp (communicative reason) như một năng lực siêu nghiệm của con người, nơi mà yêu sách về giá trị hiệu lực tồn tại nhằm giúp con người có thể thực hiện được hành động tương giao và hướng đến sự đồng thuận.

Đối với Habermas, lịch sử của nhân loại ngay từ khởi thủy đã được thẩm thấu bởi lý tính tương giao, theo ông từ xa xưa con người đã có một sự quan tâm về sự hiểu nhau. Sự hiểu biết thông qua ngôn ngữ suốt chiều dài lịch sử của nhân loại được hướng đến một sự đồng thuận phổ quát và không khiên cưỡng, một sự thỏa thuận giữa con người với nhau. Nỗ lực tìm kiếm sự đồng thuận thông qua lý tính tương giao liên tục phát triển trong lịch sử loài người dù cho luôn có những thất bại. Theo Habermas, nỗ lực tìm kiếm sự đồng thuận sẽ giúp con người từng bước giải phóng mình ra khỏi nguồn gốc thú vật, khỏi những giận dữ, chiến tranh và bóc lột lẫn nhau do chính con người gây ra, hướng đến giải quyết những xung đột của con người bằng những phương thức nhân bản. Bằng cách kiên trì với lý tính tương giao, Habermas xác tín rằng: "Dọc theo lịch sử một cơ may đích thực cho một sự phát triển hợp lý của nhân loại sẽ được thực hiện" [7].

Để kiên trì được với lý tính tương giao, để yêu sách về giá trị hiệu lực trong đối thoại được đảm bảo, theo Habermas cần phải có một hoàn cảnh nói, một không gian phát ngôn lý tưởng, Habermas gọi là diễn ngôn phi khống chế. Trong một diễn ngôn phi khống chế, ông giả định có bốn điều kiện: Thứ nhất, căn cứ vào việc những người tham gia vào đối thoại phải bỏ ra ngoài cách suy nghĩ với quyền uy và thế lực như thường thây, hoặc đặt mình trên cùng một bình diện với những người khác, làm cho mọi người được thoải mái bàn luận với nhau trên cùng một tầm trao đổi. Thứ hai, trong đối thoại mọi người phải hoàn toàn bình đẳng, tức là không chỉ trên vị thế quyền năng mà còn trên bình diện khả năng, mọi người tham gia vào đối thoại phải có được cùng một cơ hội như nhau, sử dụng cùng một hành động phát ngôn, làm cho họ luôn có thể mở lời hoặc nói ra hoặc nói lại, hoặc đặt câu hỏi hoặc đưa ra câu trả lời. Thứ ba, những người tham gia vào đối thoại đều có thể biện minh cho những luận cứ của mình, bảo vệ những luận cứ đó một cách hợp lí, ngược lại là khả năng có thể đặt nghi vấn, phê phán những luận cứ cùng những biện minh của người khác. Cuối cùng, những người tham gia vào đối thoại đều có quyền bày tỏ mong muốn và nguyện vọng, tức là khả năng đồng đều cho mọi người có thể diễn xuất ra trong cuộc trò chuyện những tình trạng cảm xúc của mình, sự thúc bách của những nguyện vọng của bản thân, "sử dụng được hành động phát ngôn về những quan điểm, cảm xúc, ý hướng của mình.” [8].

Có thể nói, một diễn ngôn phi khống chế là hoàn cảnh lý tưởng của một cuộc trò chuyện. Hoàn cảnh này "không phải là một hiện tượng thường nghiệm, cũng không phải là một sản phẩm tưởng tượng đơn thuần mà là một sự giả định dành cho nhau một cách không thể tránh khỏi trong diễn ngôn.” [9]. Hoàn cảnh này là một sự dự đoán, một ý niệm điều hướng nếu không, mọi diễn ngôn đều vô ích, không thể có hy vọng đạt đến một sự đồng thuận sáng suốt. Do đó, hoàn cảnh nói lý tưởng cũng là tiêu chí để đánh giá được phẩm chất của một diễn ngôn, và như thế cũng biết được trình độ khai phóng của một tổ chức chẳng hạn như một gia đình, một hội đoàn hay cả một xã hội.

Đến đây, Habermas đặt ra nghi vấn rằng nếu mục đích của ngôn ngữ là thấu hiểu lẫn nhau, con người giao tiếp với nhau nhằm hướng đến sự đồng thuận vậy tại sao xuyên suốt lịch sử loài người, không ít lần xảy ra các cuộc xung đột, chiến tranh triền miên chỉ vì con người không thể đi đến đồng thuận trong đối thoại. Để lý giải vấn đề này, Habermas bên cạnh lý tính tương giao đã đề xuất thêm lý tính công cụ (instrumental reason). Có thể định nghĩa ngắn gọn lý tính công cụ là những điều chúng ta không làm "trong trò chuyện với người khác đã nhìn nhận tương thông là điều đúng, nhưng lại làm điều xem ra có lợi nhất và thực tế nhất đối với bản thân ta.” [10]. Đồng thời, ứng với mỗi một loại lý tính, Habermas lại 
gán cho chúng một khu vực tồn tại khác nhau, lý tính tương giao trong thế giới đời sống (lifeworld) và lý tính công cụ trong hệ thống (system). Thế giới đời sống là: "Nơi chốn siêu nghiệm, nơi mà kẻ nói người nghe gặp gỡ nhau; nơi mà họ có thể nêu ra những đòi hỏi đối với nhau, nói với nhau những điều trùng hợp về thế giới (thế giới khách quan, thế giới xã hội, thế giới chủ quan); cũng là nơi họ có thể phê phán hay chấp nhận những yêu sách về giá trị hiệu lực này, nơi họ có thể nói lên điều bất đồng cũng như điều đồng thuận." [11].

Còn hệ thống "là một cấu trúc các yếu tố. Trong một hệ thống, các yếu tố được chọn lựa và sắp xếp có thứ tự, theo những mối quan hệ nhất định giữa chúng, theo những quy tắc nhất định. Một hệ thống được phân biệt rõ với yếu tố môi trường xung quanh." [12]. Để các yếu tố trong hệ thống, đặc biệt là hệ thống xã hội có thể vận hành trơn tru, ổn định thì mỗi yếu tố phải có quan hệ với nhau bằng cách giao tiếp, tức thực hiện hành vi tương giao. Có thể nói, thế giới đời sống là cơ sở, là nền tảng cho sự ra đời và phát triển của hệ thống.

Tuy nhiên, trong quá trình khoa học công nghệ phát triển đã làm hệ thống dần tách rời ra khỏi thế giới đời sống. Đáng nói hơn, sau khi tách ra, hệ thống đã quay ngược lại kiểm soát thế giới đời sống thông qua hai yếu tố là tiền và quyền lực, Habermas gọi đây là sự thuộc địa hóa thế giới đời sống (colonisation of the lifeworld). Ông nói: "sự xâm nhập các hình thức của lý tính kinh tế và quản trị ... đã dẫn đến ... tình trạng vật thể hóa việc thực hành tương thông hàng ngày." [13]. Vậy giờ đây giao tiếp không còn mục đích hướng đến sự thông hiểu hay đồng thuận nữa mà nó đã trở thành công cụ để đạt được lợi ích mà con người hướng đến. Giờ đây khi tham gia vào một cuộc đối thoại, mọi người đều xem nhau như là những phương tiện phục vụ cho mục tiêu của mình, những mục tiêu mà lý tính công cụ đã đưa ra.

Tóm lại, với lý thuyết về hành vi tương giao của mình, Habermas đã cảnh báo về sự thuộc địa hóa thế giới đời sống của hệ thống trong xã hội hiện đại. Quả thật, sự can thiệp của hệ thống thông qua tiền và quyền lực đã trải dài trên hẩu khắp các lĩnh vực của đời sống xã hội ngày nay từ giáo dục, $\mathrm{y}$ tế, đối ngoại cho đến các ngành thuộc về nghệ thuật. Tuy nhiên, nguy hiểm hơn hết là sự thống trị của hệ thống trong các ngành truyền thông. Để thấy được những nguy hại do hệ thống mang đến cho ngành truyền thông, trước hết cần phải xem xét học thuyết của Habermas đã mang lại những giá trị gì cho ngành này.

\section{GIÁ TRI HỌC THUYÊT VỀ HÀNH ĐỘNG TƯƠNG GIAO CỦA HABERMAS TRONG LĨNH VỰC TRUYỀ THÔNG TRÊN THẾ GIỚI NGÀY NAY}

Trong tác phẩm Truyền thông - Lý thuyết và kỹ năng cơ bản các tác giả đã định nghĩa truyền thông như sau: "Truyền thông là quá trình liên tục trao đổi thông tin, kiến thức, tư tưởng, tình cảm..., chia sẻ kỹ năng và kinh nghiệm giữa hai hoặc nhiều người nhằm tăng cường hiểu biết lẫn nhau, thay đổi nhận thức, tiến tới điều chỉnh hành vi và thái độ phù hợp với nhu cầu phát triển của cá nhân/nhóm/cộng đồng/xã hội." [14]. Theo định nghĩa của các tác giả, hoạt động truyền thông diễn ra hàng ngày trong đời sống của con người dù có nhận thức được hay không. Trong thời đại ngày nay, với sự phát triển của internet và sự trợ giúp của mạng xã hội, hoạt động truyền thông ngày càng trở nên đa dạng hơn, số người tham gia vào mạng lưới truyền thông, mạng xã hội cũng ngày một tăng lên.

Các số liệu thống kê đã cho thấy rằng, trong thời đại ngày nay, internet và mạng xã hội đã trở thành một phần thiết yếu trong đời sống hàng ngày của con người. "Trung bình mỗi giây trên Facebook có 5 tài khoản mới được khởi tạo, 3.472 bức ảnh được đăng tải, 8.500 bình luận xuất hiện và hơn 2 tỷ người đang hoạt động." [15]. Theo báo cáo của Data Never Sleep 6.0, cứ mỗi phút có 4.333 .560 video clip trên YouTube được xem và 49.380 bức ảnh được đăng trên Instagram [16]. Hay theo tổ chức We Are Social, tính đến tháng 1 năm 2019, toàn thế giới có 4,3 tỷ trong hơn 7,6 tỷ người sử dụng internet. Trong đó, có trên 3,2 tỷ người sử dụng truyền thông xã hội qua thiết bị cầm tay.

Sự ra đời và phát triển của internet đã thay đổi căn bản bộ mặt của ngành truyền thông, đặc biệt là sự "thay đổi thói quen tiêu dùng thông tin của công chúng. Khán/thính/độc giả của báo chí truyền thông hiện đang phân mảnh.” [17]. Chẳng hạn trong lĩnh vực truyền hình, trong năm 2018, thời gian bình quân một người Việt dành cho truyền hình truyền thống mỗi ngày là khoảng 2 giờ 31 phút, trong khi thời gian họ dành cho internet vào khoảng 6 giờ 42 phút (Theo báo cáo của We Are Social \& Hootsuite, 2019) [18]. Trong xã hội hiện đại, truyền hình truyền thông đã không còn gói gọn trong phòng ngủ, phòng khách của nhiều gia đình mà giờ đây chúng đã chuyển dịch lên các màn hình cảm ứng, xuất hiện trên nhiều nền tảng khác nhau và tiếp cận với khán giả ở nhiều không gian khác nhau. Khán giả giờ đây không chỉ thụ động 
nghe xem mà còn được tham gia bàn luận, góp ý ngay trong thời điểm chương trình phát sóng thông qua môi trường truyền thông xã hội.

Không chỉ có truyền hình, các hình thức truyền thông khác như báo chí đều chịu sự tác động của truyền thông trực tuyến trong bối cảnh bùng nổ các mạng xã hội. "Khi trải nghiệm của người dùng thay đổi, báo chí có sự phân hóa trong yêu cầu về chất lượng nội dung, phương thức tiếp cận thông tin." [19]. Giờ đây, người dùng không chỉ tiếp nhận thông tin một chiều từ báo chí như trước nữa mà đã trở thành trung gian chia sẻ tài nguyên thông tin của các cơ quan báo chí trong hệ sinh thái truyền thông mới.

Trước đây, chỉ có những kênh thông tin chính thống với những thành viên bên trong nó mới có tư cách là chủ thể truyền thông. Nhưng với sự ra đời của mạng xã hội, chúng đã trao cho những người bình thường không cần có nghiệp vụ báo chí nào cũng có thể trở thành chủ thể của một kênh thông tin. Có hàng ngàn Facebooker, YouTuber, Vlogger nổi tiếng sản xuất thông điệp trên nhiều lĩnh vực và thu hút hàng triệu người theo dõi. Do đó, báo chí chính thống phải biết biến công chúng, từng thành viên của mạng xã hội thành kênh truyền thông thứ cấp của mình. Với mô hình truyền thông cũ, nhà truyền thông phải tự giới thiệu, quảng bá sản phẩm, thông tin của mình thì trong hệ sinh thái truyền thông mới, chính công chúng sẽ tự động lan truyền và giới thiệu miễn phí các sản phẩm thông tin của báo chí. Công chúng vừa là đối tượng phục vụ, vừa là người tiêu dùng tin tức của báo chí, đồng thời cũng là kênh phân phối, kênh quảng cáo và là "đồng chủ thể" sáng tạo của báo chí.

Sự phát triển của công nghệ, hạ tầng viễn thông đã tạo ra lớp công chúng truyền thông đón nhận nội dung thông tin qua thiết bị cầm tay trên nền tảng mạng xã hội ngày càng tăng. Tính chất vượt biên giới của sự kết nối đã tạo ra biên độ thông tin rộng lớn và cường độ thông tin mạnh mẽ. "Chủ thể dư luận giờ đây không còn là độc quyền của cơ quan truyền thông đại chúng. Thông tin "chính thống" giờ đầy không còn là sự ban phát một chiều." [20]. Các thành viên trên mạng xã hội đã chủ động lựa chọn những nội dung mà họ quan tâm, cảm thấy là cần thiết cho bản thân. Thực tiê̂n ấy đã phá vỡ mô hình truyền thông một chiều để tạo lập hình thái chủ thể dư luận mới, vừa phân tán vừa hội tụ.

Trong mô hình truyền thông mới, báo chí khai thác mạng xã hội và các nền tảng truyền thông như những đối tác để tạo ra tương tác và lan tỏa thông điệp. Công chúng sẽ là những người đồng hành, chia sẻ trải nghiệm, đồng chủ thể sáng tạo. Thực ra đây không phải là vấn đề mới, lý thuyết về nội dung do người dùng sáng tạo (User generated content - UGC) đã được đề cập nhiều lần trong nhiều năm qua. Công việc của ngành truyền thông nói chung và báo chí nói riêng trong thời đại ngày nay chính là tạo ra một cộng đồng công chúng tích cực hơn, dân chủ hơn (trên nền tảng mạng xã hội) để họ đồng hành với cơ quan báo chí và truyền thông. Ngành truyền thông đã được định vị lại để phát huy vai trò của mình trong hệ sinh thái truyền thông mới, trong cuộc cách mạng truyền thông của kỷ nguyên internet.

Trong thời đại Cách mạng công nghiệp 4.0, các hệ thống thông minh đã tác động tích cực vào hệ sinh thái truyền thông mới. Đến lượt mình, hệ sinh thái truyền thông mới đã và sẽ làm thay đổi vai trò và vị thế của các ngành truyền thông cũng như thay đổi quy trình sản xuất của các sản phẩm truyền thông. Do đó, mô hình hoạt động, sáng tạo của truyền thông ngày nay là mô hình dựa trên sự kết nối đa nền tảng, đa hình thái, đa mạng lưới, cá nhân hóa, huy động nguồn lực của cộng đồng trong sản xuất, sáng tạo, phân phối, quảng bá, chia sẻ, v.v... sản phẩm truyền thông.

Tuy nhiên, cùng với những tác động tích cực nêu trên, đây đó trên các diễn đàn hội thảo hay báo chí, đã có nhiều ý kiến từ các cơ quan quản lý lo ngại trước sự bùng nổ của truyền thông xã hội, trước hiện tượng thao túng thông tinh, trước vấn nạn tin giả. Rõ ràng, truyền thông cá nhân và mô hình truyền thông xã hội đang trở thành một xu thế quan trọng, tuy nhiên trong nó vẫn tiềm tàng những mối nguy cơ lớn, những nguy cơ xuất phát từ những lợi ích cá nhân, sẵn sàng xem truyền thông và khách thể của hoạt động truyền thông như những công cụ đắc lực để đạt được mục đích của mình.

Giá trị của học thuyết về hành động twơng giao của Habermas đối với sự phát triển của truyền thông trong thời đại ngày nay được thể hiện ở những điểm sau:

Lý thuyết của Habermas cho thấy trong thời đại ngày nay các ngành truyền thông phải chuyển hướng hoạt động của mình bởi những khách thể của truyền thông, hay những người tiêu dùng thông tin giờ đây không còn tiếp nhận thông tin một cách thụ động, một chiều nữa. Họ hướng đến việc cùng nhau thảo luận, đặt nghi vân, đồng thuận hay bác bỏ những thông tin mà họ nhận được. Họ mong muốn một hình thức truyền thông cho họ cơ hội chủ động tiếp nhận. Quả thật, ngành báo chí nói riêng và ngành truyền thông nói 
chung trong thời đại ngày nay đã chuyển sang mô hình tham gia trong quá trình sản xuất và truyền đạt thông tin. Mô hình tham gia cho rằng truyền thông phát triển không phải là một quá trình truyền tải thông tin theo chiều dọc, từ người nói đến người nghe, mà là một quá trình trao đổi thông tin theo chiều ngang. Những người đề xướng cách tiếp cận này nhấn mạnh vai trò của các hoạt động đối thoại như chất xúc tác cho sự bình đẳng của cá nhân và cộng đồng trong những hoạt động truyền thông. Mô hình này cho rằng, mục đích của sự phát triển là để con người có quyền chủ động với những thông tin có ảnh hưởng đến họ từ đó đưa ra quyết định phù hợp; trong đó, đề cao hoạt động khuyến khích sự bình đẳng, dân chủ trong xã hội. Mục tiêu của chiến dịch truyền thông theo mô hình tham gia hướng đến việc để công chúng tự quyết định nhu cầu của họ, từ đó có thể thiết kế và tiến hành các chương trình nhằm đáp ứng những nhu cầu này, hơn là áp đặt lên hành vi của họ.

Chương trình Bũa trua vui vé phát sóng đều đặn trong khung giờ từ $12 \mathrm{~h}$ - 13h hàng ngày trên kênh VTV6 là một chương trình tiêu biểu cho mô hình truyền thông tham gia. Chương trình vừa được phát sóng trên truyền hình truyền thống, đồng thời được phát trực tiếp trên fanpage của chương trình. Mục đích của hoạt động này nhằm tạo sự tương tác tốt hơn giữa khán giả và những khách mời tham gia chương trình, khán giả vừa có thể theo dõi đồng thời cũng có thể bình luận trực tiếp trên fanpage để trao đổi, trò chuyện với khách mời hoặc tham gia các mini game do chương trình tổ chức. Đồng thời, việc để khán giả tham bình luận trực tiếp cũng nhằm tiếp thu những đóng góp của khán giả để chương trình có những điều chỉnh cho phù hợp hơn. Tính đến nay, trên fanpage của chương trình đã thu về hơn 1 triệu lượt thích, các bài đăng tạo tương tác với người xem cũng thu về kết quả tốt khi lượt thích và bình luận thường đạt mức từ 500 1000 lượt. Những kết quả đó cho thấy mọi người giờ đây không muốn là một khách thể tiếp nhận thông tin một cách thụ động nữa mà họ muốn được tham gia vào hoạt động truyền thông, muốn được đối thoại, được bày tỏ ý kiến, nguyện vọng của bản thân, muốn được trở thành một mắt xích trong mạng lưới truyền thông rộng lớn. Tóm lại, họ muốn tham gia vào như một chủ thể của truyền thông, là người tạo dựng truyền thông chứ không chỉ là một đối tượng để truyền thông hướng đến nữa.

Một hình thức khác của truyền thông tham gia đó là livestream và những người chuyên làm công việc này thường gọi là streamer, một nghề mới nổi ở Việt Nam và trên thế giới hiện nay. Những người làm nghề này công việc chính của họ là ngồi trước màn hình máy tính hoặc bất kỳ một thiết bị điện tử nào có thể phát trực tiếp được và trò chuyện, trao đổi với những người đang xem về mọi lĩnh vực trong cuộc sống. Loại hình này hiện nay rất được ưa chuộng đặc biệt là các bạn trẻ tuổi từ $15-25$ bởi họ cảm thấy chính những câu hỏi, những chia sẻ của họ với streamer đã góp phần tạo nên nội dung của buổi livestream đó. Việc đặt người truyền thông và người tiếp nhận ở một vị trí ngang hàng nhau, có thể trao đổi tương tác với nhau, cùng nhau cải thiện chất lượng của hoạt động truyền thông đã đem lại những tín hiệu tốt cho loại hình này. Hiện nay, các streamer nổi tiếng như Độ Mixi (Phùng Thanh Độ) hay Ninja (Tyler Blevins) đều đạt lượt xem trực tiếp trung bình từ 100000 đến 150000 cho mỗi buổi stream; các streamer nổi tiếng khác cũng đạt mức từ 10000 đển hơn 50000 lượt xem là những dấu hiệu cho thấy sự phát triển mạnh của loại hình livestream nói riêng và mô hình tham gia nói chung.

Với sự xuất hiện của mô hình tham gia cùng sự hỗ trợ của mạng xã hội, ngành truyền thông đã tạo lập ra một không gian truyền thông hoàn toàn mới. Đặc trưng nổi bật của không gian mới này là công chúng từ những đại chúng nặc danh, không có kết nối khi tham gia vào không gian truyền thông bắt buộc phải có danh tính rõ ràng để có thể kết nổi được với các cá nhân khác, tạo nên một mạng lưới quen biết lẫn nhau. Chẳng hạn, để có thể tham gia tương tác, bình luận, chia sẻ thông tin với các chương trình phát trực tuyến mỗi người đều phải có một danh xưng hay một cái tên cho riêng mình. Việc tạo một danh xưng cho bản thân trên mạng xã hội có thể khớp hoặc không khớp với bản thân mình ngoài xã hội thực nhưng với danh xưng đó, mọi người đã tự định hình chính mình trên không gian mạng xã hội, mở ra sự kết nối với những người khác, trút bỏ tính nặc danh. Với mạng lưới này, hoạt động cung cấp và phân phối tin tức không còn đi theo hướng truyền thống, tức từ một phương tiện truyền thông "phủ" lên đám đông, mà theo kiểu lan tỏa từ cá nhân này sang cá nhân khác trong chính mạng lưới quen biết của họ. Trong môi trường truyền thông mới, công chúng từ những người nặc danh, không có liên kết với nhau giờ đã kết nối với nhau bởi "các mối quan hệ cá nhân vô cùng đa dạng (...) từ đồng nghiệp đến gia đình, từ bạn đến bạn của bạn (...), hoặc gắn kết trong các nhóm cùng chung công việc, nơi sinh sống, sở thích, mối quan tâm..." [21]. Không gian truyền thông mới này, có thể được gọi là "không gian công trong thời đại internet". Một 
không gian mà mọi người có thể cùng nhau tranh luận một cách có suy nghĩ và có tính thuyết phục dựa trên những mối quan tâm đến chân lý và lợi ích chung.

Lý thuyết hành động tương giao của Habermas cùng với mô hình tham gia cho ta thấy rõ rằng truyền thông là hoạt động hai chiều, người tiếp nhận thông tin đồng thời cũng có thể là người sản xuất thông tin, sản xuất nội dung tác động ngược trở lại người truyền đạt thông tin trước đó. Ở thế kỷ XXI, kỷ nguyên của internet và mạng xã hội, tính hai chiều trong hoạt động tương giao ngày càng phát huy rõ rệt hơn bao giờ hết. Hành vi tiếp nhận thông tin của công chúng đã có những thay đổi sâu sắc, bên cạnh việc tiếp nhận thông tin, công chúng giờ đây còn có khả năng tham gia vào quá trình tạo ra và chia sẻ nội dung (UGC). Người dùng trong thời đại internet đồng thời cũng là những người tạo ra, phát tán, tương tác và chia sẻ các luồng thông tin trên mạng xã hội. Trong số những người dùng này, có những người đóng góp nhiều cho nội dung, có người tích cực trong việc chia sẻ và phản hồi. Điểm phát của họ có thể là những điểm có ảnh hưởng và tạo hiệu ứng cũng như mức lan tỏa trên internet. Khi những người sử dụng thông tin được trao vào tay những quyền được bình luận, trao đổi hay chất vấn những nội dung truyền thông được tạo ra trên mạng xã hội, họ ngày càng trở nên chủ động hơn trong việc tiếp nhận, phát tán thông tin hay chất vấn, phê phán những thông tin mà họ cho là sai sự thật hay có nội dung độc hại. Từ đó, người sử dụng thông tin buộc những người sáng tạo tin tức phải thay đổi nội dung truyền thông hoặc là họ sẽ bị đào thải. Trường hợp vlogger được nhiều người biết đến đã quay video trong khu rừng tự sát Aokigahara nổi tiếng của Nhật Bản và có những hành vi cười cợt với thi thể trong khu rừng hay gần đây nhất là một tuyển thủ chuyên nghiệp của bộ môn esport Liên Minh Huyền Thoại ở Việt Nam đã có những phát ngôn không đúng mực về đại dịch Covid khi đang trên sóng livestream. Tất cả đều đã vấp phải sự phẫn nộ của những người sử dụng thông tin khi họ cảm thấy những nội dung họ tiếp nhận được là hoàn toàn độc hại. Người sử dụng thông tin liên tục chất vấn, phê phán và yêu cầu những bên có thẩm quyền xử lý những sự việc trên. Kết quả vlogger phải lên tiếng xin lỗi vì hành vi của mình và mất đi một lượng lớn người theo dõi, còn tuyển thủ chuyên nghiệp kia thì bị cấm thi đấu vĩnh viễn bởi tổ chức VCS. Đây là hai trong nhiều trường hợp mà quyền của người sử dụng thông tin được sử dụng triệt để nhằm điều chỉnh các hoạt động truyền thông cho phù hợp với nhu cầu của họ. Nếu mổ hình tham gia và quyền của người sử dụng thông tin tiếp tục được nhân rộng, thậm chí áp dụng vào các kỳ họp Quốc hội thì nền dân chủ xã hội chủ nghĩa ở Việt Nam sẽ không ngừng được mở rộng.

Bên cạnh đó, với sự xuất hiện của ứng dụng Web 2.0 ta nhận thấy "có sự thay đổi về mô hình một cách rõ ràng trong phương thức sản xuất và lưu hành nội dung truyền thông.” [22] (Nhiều tác giả, 2020, tr.135). Công chúng được trao quyền thông qua công nghệ mới. Từ đó, họ có cơ sở để tạo ra, tương tác và chia sẻ những nội dung mà họ muốn. Để thấy được tính tích cực của cộng đồng người dùng sáng tạo nội dung, một loạt các nghiên cứu vào khảo sát về mức độ sử dụng mạng xã hội của công chúng đã được tiển hành. Trong đó, theo báo cáo của Omnicore, năm 2018 có khoảng 150 triệu giờ video trên YouTube được xem mỗi ngày. YouTube thu hút khoảng $1 / 3$ người dùng internet trên toàn cầu và có khoảng 50 triệu người tham gia sáng tạo nội dung trên YouTube. Ở một nghiên cứu khác, sau một thời gian quan sát, phóng viên công nghệ Charles Arthur của tờ The Guardian đã rút ra một quy tắc mới: Nếu một nhóm gồm 100 người trực tuyến thì có một người sáng tạo nội dung, 10 người tương tác và 89 người khác chỉ đơn thuần là xem nội dung [23]. Điều này cho thấy có nhiều cấp độ khác nhau khi nói về sự tham gia của người dùng. Tuy nhiên, những khảo sát trên đã chỉ ra rằng công chúng trong thời đại internet và mạng xã hội đã năng động hơn rất nhiều, bản thân họ đã trở thành một kênh thông tin, một chủ thể sáng tạo nội dung chứ không đơn thuần là người tiếp nhận nội dung đơn hướng, thụ động như trước đây nữa.

Quá trình sáng tạo nội dung của người dùng phát triển mạnh mẽ đã dẫn đến sự ra đời của những người hoạt động như một KOLs (Key opinion leader - người định hướng dư luận) hay còn gọi là những người có ảnh hưởng trên mạng xã hội, có nhiều lượt theo dõi, có thể tiếp cận nhiều công chúng không thua kém các hãng tin tức nổi tiếng. Trong xã hội, có một bộ phận những người có tầm ảnh hưởng, có khả năng phân tích và nắm bắt tình hình. Những người này thường có tầm nhìn rộng và sâu, có kiến thức bao quát để xem xét và đánh giá vấn đề. Nội dung họ tạo ra trên internet có thể dẫn đầu để khơi dậy một làn sóng tư tưởng, định hướng dư luận hay đơn giản là hoạt động độc lập để phản ứng với tình huống xảy ra theo một cách nào đó.

Tuy nhiên, khi người dùng có khả năng sáng tạo nội dung, một lượng thông tin khổng lồ được tạo ra gây nên tình trạng bội thực thông tin, mất kiểm soát thông tin. Từ đó, tin giả có môi trường thuận lợi để bành 
trướng trên khắp các nền tảng mạng xã hội và được lan truyền với tốc độ chóng mặt. Vấn nạn đó đặt ra thách thức lớn với các cơ quan báo chí lẫn công chúng tiêu dùng thông tin phải nhận biết được đâu là những tin tức chính thống và đâu là tin giả, tin tức bị điều hướng.

Trước những thách thức do sự phát triển của truyền thông đặt ra, Habermas đã từng cảnh báo về sự thuộc địa hóa thế giới đời sống của hệ thống, đặc biệt là trong lĩnh vực truyền thông, bởi những lợi ích cá nhân mà con người hướng đến. Biểu hiện của sự thuộc địa hóa này là vấn nạn tin giả và sự kiểm soát thông tin trong quá trình truyền thông vì một lợi ích nào đó mà người sản xuất thông tin hướng đến. Theo Habermas, trong quá trình tham gia vào đối thoại, nếu truyền đạt thông tin không đúng sự thật cố tình che giấu những yếu tố chính trong thông tin truyền đạt tức là người sản xuất thông tin đã vi phạm vào yêu sách giá trị hiệu lực do ông đề xuất gồm yêu sách về sự chân thành và yêu sách về tính chân lý, tức cuộc đối thoại đó đã trở nên vô nghĩa, thông điệp được truyền đạt giờ đây không gì khác hơn là một lợi ích cá nhân đơn thuần.

Nhưng để nhận ra đâu là tin giả không phải là việc làm đơn giản, nếu chỉ dựa vào yêu sách giá trị hiệu lực hay giả định hoàn cảnh nói lý tưởng của Habermas không thôi là chưa đủ. Trước hết, cần phải hiểu về tin giả cũng như lịch sử tồn tại của nó:

Tin giả (fake news) là tin tức được đưa ra không dựa trên sự thật, hoặc chỉ dựa trên một phần sự thật, hoặc phóng đại sự thật, hoặc bóp méo sự thật để dẫn dụ công chúng đi theo ý đồ của chủ thể thực hiện truyền thông. [24].

Tin giả tồn tại như một phần tất yếu của đời sống xã hội bởi con người thường hiếu kỳ trước những câu chuyện mới lạ, bất ngờ, đầy tính kích thích về thế giới khách quan xung quanh mình. Tin giả ra đời đã đáp ứng được lòng hiếu kỳ đó của con người khi liên tục vẽ ra những câu chuyện mới lạ, đầy sự kích thích dù cho không đúng sự thật. Hoặc, một số cơ quan sản xuất thông tin sử dụng tin giả như một công cụ đắc lực để định hướng dư luận nhằm những mục đích như giải trí, cạnh tranh, trả thù,.... với đích đến cuối cùng là đem lại lợi ích cho bản thân mình, ở đây có thể hiểu là lợi ích về tiền bạc và quyền lực.

Tin giả xuất hiện trước cả khi ngành báo chí và truyền thông ra đời, dưới dạng truyền miệng, tin đồn, tin rỉ tai,.... Chẳng hạn ở Việt Nam thời nhà Lê diễn ra vụ thảm án Lệ Chi Viên (1442) khiến Nguyễn Trãi và gia đình ông bị tru di tam tộc cũng chính là do một dạng tin giả được lan truyền dưới dạng lời đồn, tin rỉ tai trong chốn cung đình. Khi báo chí ra đời và phát triển, với những yêu cầu khắt khe về đạo đức nghề báo cũng như ý thức của những người làm nghề chuyên nghiệp, tin giả dù vẫn còn tồn tại nhưng sẽ rất nhanh bị phát hiện và loại bỏ, tránh cho người đọc tiếp nhận nhiều nhất có thể. Tuy nhiên, trong thời đại của mạng xã hội, nơi mà mọi người đều được trao quyền sáng tạo nội dung, sản xuất thông tin mọi chuyện đã trở nên phức tạp hơn. Khi thông tin bùng nồ, một khối lượng lớn thông tin được tạo ra hàng ngày đã khiến người tiêu dùng không biết phải lựa chọn những nguồn tin nào trong vô số nguồn tin trôi nổi trên mạng xã hội. Trong chính điều kiện đó, tin giả có cơ hội bành trướng mạnh mẽ, "sinh sôi nảy nở" như một chủng virus độc hại trong ngành truyền thông. Để thấy được tính nguy hiểm của tin giả, có thể viện dẫn đến dịch bệnh Covid-19 khi nó mới bùng phát ở Việt Nam. Lợi dụng tâm lý lo sợ của người dân trước tính chất nghiêm trọng của dịch bệnh cùng với sự thiếu hiểu biết về chủng virus mới này, hàng loạt tin tức giả được những người sản xuất thông tin, kể cả có cả những thông tin của người nổi tiếng. Trong đó, nội dung chủ yếu là thống kê về số người nhiễm bệnh, số người chết không đúng với số liệu thật nhằm gây hoang mang cho những người tiếp nhận thông tin nhằm đạt được một số mục đích cá nhân như giải trí đơn thuần, gia tăng lợi nhuận hay nặng nề hơn là kích động người dân, làm cho họ mất niềm tin vào Chính phủ Việt Nam. Dù cho với mục đích nào, tin giả cũng đã gây ra những hậu quả nghiêm trọng cho cả người sản xuất tin tức lẫn người tiêu dùng thông tin, nhẹ thì chỉ đơn giản là những cuộc tranh cãi không hồi kết trên mạng xã hội nhưng nặng thì sẽ tổn hại đến uy tín của những người, những cơ quan liên quan hay trầm trọng hơn là uy tín của cả một quốc gia.

Trong cuộc chiến chống tin giả, xóa bỏ hoàn toàn tin giả là một việc làm bất khả, chừng nào con người vẫn còn hiếu kỳ với những câu chuyện mới lạ và kích thích, chừng nào hệ thống tiền và quyền lực vẫn còn len lỏi và kiểm soát thế giới đời sống của con người thì chừng đó vấn nạn tin giả vẫn còn tồn tại và phát triển mạnh mẽ. Việc có thể làm lúc này là tăng cường khả năng nhận biết tin giả của người tiêu dùng từ đó từ chối tiếp nhận nó. Bên cạnh đòi hỏi những yêu sách về giá trị hiệu lực phổ quát hay giả định hoàn cảnh nói lý tưởng trong đối thoại do Habermas đề xuất, người tiêu dùng thông tin còn có thể nhận biết tin 
giả thông qua việc nỗ lực hiểu ý nghĩa của thông tin được truyền đạt thông qua việc nhận biết hậu cảnh của thông tin đó ngay lúc nó được sản xuất. Ngoài nỗ lực của người tiêu dùng, các cơ quan báo chí cũng đóng vai trò quan trọng trong cuộc chiến này, họ không ngừng tạo dựng uy tín, gây dựng niềm tin đối với công chúng nhằm giúp công chúng có được những nguồn tin chính thống khi cần biết về một vấn đề gì. Tóm lại, cuộc chiến chống tin giả là cuộc chiến của cả người tiêu dùng lẫn các cơ quan báo chí, nơi đó, lý thuyết của Habermas đóng vai trò như một sự hỗ trợ đắc lực thông qua lý tính tương giao, một bản năng siêu nghiệm tồn tại nơi con người.

\section{KẾT LUẬn}

Ra đời vào thế kỷ XX, lý thuyết hành vi tương giao của Habermas là một nỗ lực hướng đến sự thấu hiểu lẫn nhau của con người thông qua yêu sách về giá trị hiệu lực cũng như những hoàn cảnh nói lý tưởng. Được biết đến đầu tiên là một học thuyết triết học nhưng càng về sau, mức độ ảnh hưởng của học thuyết này càng lớn, nó lan sang các lĩnh vực khác mà đặc biệt là được áp dụng vào lĩnh vực truyền thông. Nhất là trong giai đoạn phát triển mạnh mẽ của internet và mạng xã hội, học thuyết của Habermas càng đóng vai trò quan trọng hơn khi nó cung cấp cho những người tiêu dùng thông tin một bộ công cụ để tra vấn các vấn đề truyền thông khi mà truyền thông đang dần chuyển sang một mô hình năng động hơn, cho phép mọi người ai cũng được tham gia vào quá trình truyền thông, tạo thành một mạng lưới truyền thông rộng rãi hơn đồng thời cũng kéo theo nhiều thách thức hơn. Những công cụ được cung cấp bởi học thuyết của Habermas hay chính bản thân học thuyết của ông không nhằm thay đổi hay loại bỏ các vấn nạn trong truyền thông, nó chỉ giúp người tiêu dùng thông tin tỉnh táo hơn, sáng suốt hơn trong quá trình tiếp nhận cũng như tham gia vào hoạt động truyền thông. Tuy vẫn còn nhiều hạn chế trong lý thuyết của mình chẳng hạn như, nguy cơ về một cuộc đối thoại vô tận hay nghi vấn về tính hiện thực của hoàn cảnh nói lý tưởng,... nhưng vẫn không thể phủ nhận được những giá trị to lớn của nó đối với ngành truyền thông trong thời đại hiện nay cũng như trong đối thoại hàng ngày của con người.

\section{TÀI LIỆ THAM KHẢO}

[1] Walther Ziegler, Habermas trong 60 phút. (Luu Hồng Khanh dịch), tr.12, Nxb.Hồng Đức, 2021.

[2] Walther Ziegler, Habermas trong 60 phút. (Luu Hồng Khanh dịch), tr.15, Nxb.Hồng Đức, 2021.

[3] Walther Ziegler, Habermas trong 60 phút. (Luu Hồng Khanh dịch), tr.17, Nxb.Hồng Đức, 2021.

[4] Andrew Edgar, Tù điển triết học Habermas. (Nguyễn Đắc Kiên dịch), tr.212, Nxb. Khoa học Xã hội, 2018.

[5] Andrew Edgar, Tù điển triết học Habermas. (Nguyễn Đắc Kiên dịch), tr.16, Nxb. Khoa học Xã hội, 2018.

[6] Walther Ziegler, Habermas trong 60 phút. (Luu Hồng Khanh dịch), tr.57, Nxb.Hồng Đức, 2021.

[7] Walther Ziegler, Habermas trong 60 phút. (Luu Hồng Khanh dịch), tr.60, Nxb.Hồng Đức, 2021.

[8] Walther Ziegler, Habermas trong 60 phút. (Luu Hồng Khanh dịch), tr.68, Nxb.Hồng Đức, 2021.

[9] Bùi Văn Nam Sơn, Trò chuyện triết học, tập 9, tr.32, Nxb.Tri thức, 2020.

[10] Walther Ziegler, Habermas trong 60 phút. (Luu Hồng Khanh dịch), tr.83, Nxb.Hồng Đức, 2021.

[11] Walther Ziegler, Habermas trong 60 phút. (Luu Hồng Khanh dịch), tr.84, Nxb.Hồng Đức, 2021.

[12] Nguyễn Xuân Nghĩa, Lý thuyết xã hội đương đại. Một số nhà tư tưởng quan trọng tù nưa cuối thế kỷ XX đến nay, tr.203, Nxb. Đại học Quốc gia, 2017.

[13] Walther Ziegler, Habermas trong 60 phút. (Luu Hồng Khanh dịch), tr.107, Nxb.Hồng Đức, 2021. 
[14] Nguyễn Văn Dững, Đỗ Thị Thu Hằng, Truyền thông - Lý thuyết và kỹ năng co bản, tr.14, Nxb.Thông tin và Truyền thông, 2018.

[15] Nhiều tác giả, Báo chí và Truyền thông. Nhũng thách thức và giải pháp trong xu thế phát triển hiện đại, tr.10, Nxb.Đại học Quốc gia, 2020.

[16] Domo, Data Never Sleeps 6.0 (Báo cáo khảo sát dũ liệu truyền thông 2020). Truy cập tại https://www.domo.com/learn/data-never.sleeps-6, 2020.

[17] Nhiều tác giả, Báo chí và Truyền thông. Nhũng thách thức và giải pháp trong xu thế phát triển hiện đại, tr.10, Nxb.Đại học Quốc gia, 2020.

[18] WeAreSocial, \& Hootsuite, Digital Vietnam 2019 (Báo cáo Nghiên cưu thị truò̀ng truyền thông số), truy cập tại https://drive.google.com/file/d/15mvrxj624b2wlNv8W2O_oqzpQkfBEXvr/view, 2019.

[19] Nhiều tác giả, Báo chí và Truyền thông. Nhũng thách thức và giải pháp trong xu thế phát triển hiện đại, tr.11, Nxb.Đại học Quốc gia, 2020.

[20] Nhiều tác giả, Báo chí và Truyền thông. Nhũng thách thức và giải pháp trong xu thế phát triển hiện đại, tr.17, Nxb.Đại học Quốc gia, 2020.

[21] Nhiều tác giả, Báo chí và Truyền thông. Nhũng thách thức và giải pháp trong xu thế phát triển hiện đại, tr.55, Nxb.Đại học Quốc gia, 2020.

[22] Nhiều tác giả, Báo chí và Truyền thông. Nhũng thách thức và giải pháp trong xu thế phát triển hiện đại, tr.135, Nxb.Đại học Quốc gia, 2020.

[23] Charles Arthur, What is the 1\% rule?, The Guardian, truy cập tại https://www.theguardian.com/technology/2006/jul/20/guardianweeklytechnologysection2, 2016.

[24] Nhiều tác giả, Báo chí và Truyền thông. Nhũng thách thức và giải pháp trong xu thế phát triển hiện đại, tr.110, Nxb.Đại học Quốc gia, 2020.

Ngày nhận bài: 28/04/2021

Ngày chấp nhận đăng: 16/07/2021 